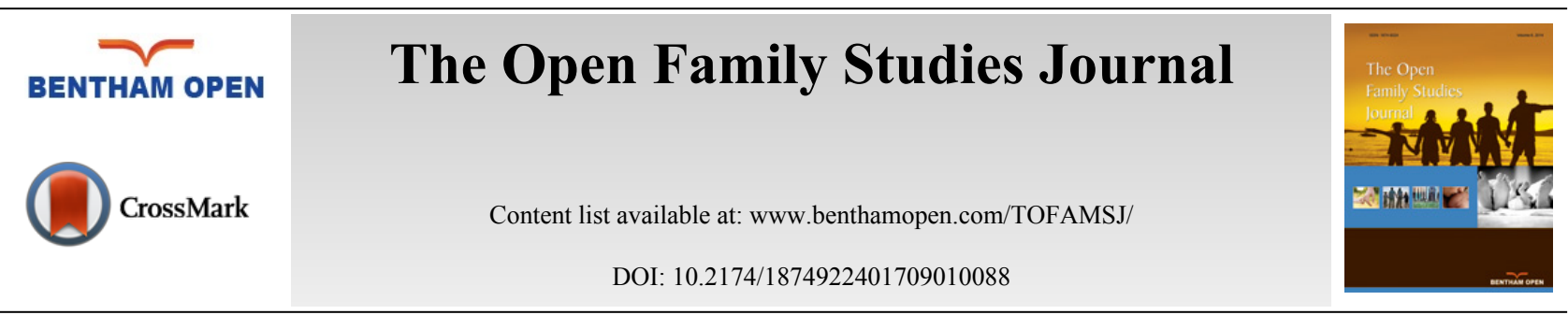

EDITORIAL

\title{
Qualitative Explorations of Family-School Relationships Regarding Children with Emotional and Behavioral Disorders (EBD) and Reactive Attachment Disorder (RAD)
}

This special issue includes a set of 7 general articles on this topic from different academic fields, which coalesce with a focus on family and school interactions and a qualitative research perspective and/or consideration of ways in which the qualitative methodology might further support the literature in this area. The studies and manuscripts in this themed issue include research articles and conceptual argument articles that express the work of behavior and family specialists and academics in the areas of education and psychology.

The article entitled, "The introduction of emotion coaching as a whole school approach in a primary specialist social emotional and mental health setting: Positive outcomes for all," Gus, Rose, Gilbert, and Kilby highlighted the potential of adopting a whole school approach to attachment awareness in meeting the needs of students with attachment issues. They discussed the findings of a case study into the use of emotion coaching across a special school as a means of shaping an attachment aware school that aids students in developing their emotional awareness. Significantly, the authors displayed a positive impact of the use of emotion coaching on student self-regulation. In addition, emotion coaching was observed to build positive interactions between the school and family.

Wenger, Crump, LaFollette, and Kurtz reported on a literature review of research on students with EBD and/or RAD in "Explorations of family-school relationships regarding children with RAD and/or EBD: TA review of relevant literature from 1995-present." The authors shed light on the kinds of qualitative investigations on school and family relationships that have been undertaken in the areas of EBD and RAD over the past 15 years.

In "Understanding parent-school communication for students with emotional and behavioral disorders," Buchanan and Clark identified communication patterns between parents and schools and considered barriers to interactions between parents and schools regarding advocacy for students with EBD. Importantly, school type and school culture were seen affect the quality and quantity of such home-school relationships. Moreover, recommendations were provided to aid in establishing proactive and successful communication patterns between all schools and families.

The article entitled, "Effectiveness of therapeutic attachment camps for improving behavior in children with Reactive Attachment Disorder," Coleman and Coleman provided a psychotherapeutic lens to the issues of attachment. In their work, they examined the findings of an inquiry into the Families by Design, Healing Heart Camps, which is highlighted as a successful intensive therapy family camp that is targeted at attachment among children with RAD.

In a title, "How are we doing?: Family-school relationships and children with Reactive Attachment Disorder," Taft and Schlein employed the principles of effective partnership as a lens to consider the type and quality of communication between families and schools with respect to children with RAD. Effective partnership principles were used to analyze the experiences of families with schools. The findings of their narrative inquiry underscored the need for increased and enhanced communication between schools and families with children with RAD.

Rose, Gilbert, McGuire-Snieckus, Gus, McInnes, and Digby examined the findings of a case study into the application of the Attachment Aware Schools project as a whole school approach to improving parental engagement with schools in "Attachment Aware Schools: Working with families to enhance parental engagement and home-school relationships." Significantly, the study results indicated that the Attachment Aware Schools model resulted not only in effective relationship-building between families and schools, but it also led to more positive within-family relationships. 
Candace Schlein

UMKC School of Education

324 Education Bldg., 615 E.52nd St., Kansas City, MO. 64110, USA

E-mail: schleinc@umkc.edu

Raol J. Taft

University of Missouri-Kansas City

USA

E-mail: taftr@umkc.edu

(C) 2017 Candace Schlein.

This is an open access article distributed under the terms of the Creative Commons Attribution 4.0 International Public License (CC-BY 4.0), a copy of which is available at: https://creativecommons.org/licenses/by/4.0/legalcode. This license permits unrestricted use, distribution, and reproduction in any medium, provided the original author and source are credited. 